Canadian Journal of Fisheries and Aquatic Sciences

Canadian Science Publishing

Journal canadien des sciences halieutiques et aquatiques

\title{
Predator-prey dynamics mediate long-term production trends of Cisco (Coregonus artedi) in a northern Wisconsin lake
}

\begin{tabular}{|r|l|}
\hline Journal: & Canadian Journal of Fisheries and Aquatic Sciences \\
\hline Manuscript ID & cjfas-2017-0302.R2 \\
\hline Manuscript Type: & Article \\
\hline Date Submitted by the Author: & $27-$ Feb-2018 \\
\hline $\begin{array}{r}\text { Complete List of Authors: } \\
\text { Is the invited manuscript for } \\
\text { consideration in a Special } \\
\text { Issue? : }\end{array}$ & $\begin{array}{l}\text { Parks, Timothy; Wisconsin Department of Natural Resources, } \\
\text { } \text { of Wisconsin Madison Center for Limnology, }\end{array}$ \\
\hline Keyword: & $\begin{array}{l}\text { CISCO, ACOUSTICS < General, PELAGIC < Environment/Habitat, FISH } \\
\text { PRODUCTION, PREDATOR-PREY INTERACTION < General }\end{array}$ \\
\hline &
\end{tabular}


1 Predator-prey dynamics mediate long-term production trends of Cisco

2 (Coregonus artedi) in a northern Wisconsin lake

4 Authors: Timothy P. Parks ${ }^{1 *}$ and Andrew L. Rypel ${ }^{2}$

5

$6{ }^{1}$ Wisconsin Department of Natural Resources, Office of Applied Science, 810 W Maple

7 St, Spooner, Wisconsin USA 54801

8

$9 \quad{ }^{2}$ Wisconsin Department of Natural Resources, Office of Applied Science, 2801

10 Progress Road, Madison, Wisconsin USA 53716

11

12 *corresponding author: email: timothy.parks@wisconsin.gov 
13 Abstract: We quantified production, biomass, and P/B ratios for cisco (Coregonus

14 artedi) in Trout Lake, Wisconsin USA (2001-2015). Across all years, annual production,

15 biomass, and P/B were variable ranging $0.6-30.2 \mathrm{~kg} \cdot \mathrm{ha}^{-1} \cdot \mathrm{y}^{-1}, 1.2-39.7 \mathrm{~kg} \cdot \mathrm{ha}^{-1}$, and $0.4-$

$160.9 \mathrm{y}^{-1}$, respectively. Cisco production exhibited obvious decline. However, neither

17 biomass nor P/B changed significantly over time. Long-term patterns of environmental

18 conditions remained unchanged during the study, and were unrelated to cisco

19 production. However, lake trout (Salvelinus namaycush) relative abundance showed a

20 strong inverse relationship with cisco production and biomass. Intense lake trout

21 stocking has occurred in this lake over time to conserve a genetically unique strain of

22 the species. These management efforts may have had the unintended consequence of

23 amplifying top-down predation on cisco. Since cisco P/B has gone largely unchanged,

24 cisco production would be predicted to rebound quickly to adaptive reductions in lake

25 trout stocking. Further increases in lake trout numbers could place both populations at

26 risk of collapse. This study provides an example of a fisheries production approach for

27 understanding and conserving cold-water fisheries, especially in lakes dominated by

28 ciscoes. 


\section{Introduction}

Secondary production is a classic and potentially unifying theme in fisheries science (Ricker 1946; Waters 1977, 1992; Dolbeth et al. 2012; Rypel and David 2017).

32 Fisheries production is defined as the rate of elaboration of new fish biomass in a population or assemblage which is indicative of a species ecological success in an ecosystem (Kwak and Waters 1997; Dolbeth et al. 2012). Specifically, production rates integrate critical rate functions such as mortality, growth and recruitment, and are therefore extremely responsive to environmental influences (Waters 1992; ValentineRose et al. 2007; Rypel and David 2017). This capability to reflect rate functions makes production measures appealing to fish managers, since they can be used to answer a variety of questions ranging from fisheries sustainability (Colvin et al. 2012; Rypel et al. 2015) to habitat importance (Rawson 1952; Kwak and Waters 1997; Lobón-Cerviá et al. 2011). Commonly, fish biologists estimate biomass as the amount of living fish tissue available per unit area as an indirect measure of fish production. However, biomass is a static variable, whereas production is dynamic and literally describes the flux of biomass

44 which characterizes fish productivity (Dolbeth et al. 2012; Rypel and David 2017). Additionally, production to biomass $(\mathrm{P} / \mathrm{B})$ ratios measure the productive capacity of populations and habitats by describing population replacement rates (Randall and

47 Minns 2000). For example, P/B ratios explicitly quantify the amount of production in a 48 population that is independent of biomass (Waters 1977), and since P/B is

49 mathematically expressed in units of inverse time, it represents a pure ecological statistic (Charnov 1993). 
Cisco (Coregonus artedi) is an obligate cold-water species, native to glacial lakes

53 in the upper latitudes of North America (Scott and Crossman 1973). Populations of the

54 species are of great importance to fisheries because of their role in food web dynamics

55 of cold-water lakes (Rudstam et al. 1993; Ebener 1995; Henderson et al. 2004). For example, lakes with robust cisco populations have a positive influence on the growth

57 dynamics of northern pike (Esox lucius), lake trout (Salvelinus namaycush), and walleye

58 (Sander vitreus) compared to lakes with other prey bases characterized by lower energy densities (Matuszek et al. 1990, Jacobson 1992, Kaufman et al. 2009). Additionally, as

60 planktivores, cisco can effectively regulate zooplankton assemblage structure and

61 mediate water quality via middle-out trophic cascades (Vanni et al. 1990; Rudstam et al.

62 1993; Lathrop et al. 2002). Cisco populations are also indicative of environmental

63 change more generally. They are sensitive to temperature and water quality, because

64 oxythermal conditions are narrowed in lakes during summer months (Jacobson et al.

65 2008; Jacobson et al. 2010; Jiang et al. 2012; Fang et al. 2012; Jacobson et al. 2012).

66 For example, cisco are in decline across the southern edge of their range, a trend that is

67 being driven by a combination of warming lake temperatures and land use change

68 (Jacobson et al. 2012; Honsey et al. 2016; Rypel et al., unpublished data).

69 Because of the seasonally pelagic distribution of cisco in lakes, this species has

70 been notoriously difficult to survey. Hydroacoustics and vertical gillnets have been

71 standard assessment tools for measuring and monitoring cisco and other pelagic fish

72 populations in glacial lakes (Rudstam et al. 1993; Milne et al. 2005, Hrabik et al. 2006).

73 Researchers have typically limited their research to relatively simple comparisons of

74 cisco abundance and biomass (Rudstam et al. 1993; Lathrop et al. 2002). Yet these 
75 metrics are static in the sense that they represent ecological snapshots at a given point

76 in time, whereas production and P/B capture dynamic rate functions and energy flux.

77 Myers et al. (2015) recently suggested that cisco recruitment dynamics in lakes should

78 be quantified solely based on hydroacoustics as opposed to traditional gears (e.g., gill

79 nets or mid-water trawl); thus, the potential exists for capturing production dynamics via

80 hydroacoustics. Briefly, mobile hydroacoustics surveys utilize active sound to measure

81 the abundance and biomass of pelagic fish populations in large waterbodies via

82 backscatter of the swim bladders of resident fishes. Estimation of production requires

83 estimates of abundance, size-structure, body mass, and growth rates. Abundance and

84 size-structure are obtainable through the use of hydroacoustics. Hence, studies of

85 hydroacoustics and fish production are compatible. Many have utilized this information

86 to derive fish estimates of pelagic fish biomass (Rypel and David 2017), but few have

87 utilized hydroacoustic methods to empirically calculate production (Schulz et al. 2004).

88 Studies of pelagic prey bases in lakes, particularly long-term studies, are

89 valuable for management of fisheries. For example, hydroacoustics surveys are

90 extensively utilized in the study and management of the Laurentian Great Lakes

91 fisheries (Fabrizio et al. 1997; Mason et al. 2005). Here, pelagic prey are monitored

92 over time to detect and prevent over-depletion of prey resources by stocked salmonids,

93 and to subsequently adjust harvest and stocking rates as needed to ensure fishery

94 sustainability (Stewart et. al. 1981; Tsehaye et al. 2014). However, smaller inland lake

95 fisheries are rarely managed in this tradition, even though connected pelagic-littoral

96 fisheries are common in lakes across the globe (Vander Zanden and Vadeboncoeur

97 2002; Tunney et al. 2014). Food web (e.g., Ecopath with Ecosim) and bioenergetics 
98 modelling are two approaches that have been used to infer predator-prey interactions 99 within lakes (e.g., Stewart et. al. 1981; Cox and Kitchell 2004). However, these models 100 are complex, and tend to rely on a host of assumptions regarding fish production, 101 biomass, and P/B ratio values (Hansen et al. 1993; Christensen and Walters 2004; 102 Dolbeth et al. 2012). Empirical examinations of predator-prey production dynamics 103 could offer an additional path towards better understanding and management of lakes 104 with pelagic food webs. First, estimation of production dynamics could allow for 105 improved parametrization of food web models. Second, important ecological patterns 106 may be empirically detectable, if production dynamic data are temporally explicit.

107 Finally, empirical trends in data are sometimes more easily explained to stakeholders 108 and managers with limited mathematical backgrounds (Dolbeth et al. 2012). Yet the 109 data required to perform such studies are potentially rare due to the expense and 110 difficulty associated with long-term data collection (Magnuson et al. 2006).

111 The goals of our study were to 1) quantify annual production, biomass and $P / B$

112 for cisco in Trout Lake for all years when hydroacoustic data were available; 2) evaluate 113 long-term trends in production, biomass and P/B of cisco in Trout Lake; and 3) examine 114 potential ecological and food web drivers of long-term cisco production dynamics.

116 Methods

\section{Study site}

Trout Lake is a 1564 ha drainage lake (mean and maximum depth $=14.9 \mathrm{~m}$ and $35.7 \mathrm{~m}$, respectively) located in Vilas County, Wisconsin. Cisco are by far the most 120 numerous pelagic species in the lake (Ahrenstorff et al. 2013). Aside from cisco, other 
121 common fish species include muskellunge (Esox masquinongy), bluegill (Lepomis 122 macrochirus), yellow perch (Perca flavescens), largemouth bass (Micropterus

123 salmoides), smallmouth bass (Micropterus dolomieu), walleye, northern pike (Esox 124 lucius), lake trout, and lake whitefish (Coregonus clupeaformis). The watershed is 125 primarily forest (51\%), wetland (19\%) and open water (24\%), and a small amount of low 126 intensity and open space (5\%) development, being primarily cottages and vacation 127 homes. It is one of only two lakes in Wisconsin known to have historically supported 128 naturally reproducing lake trout. A variety of studies have been conducted on Trout 129 Lake over time because it is part of the Northern Temperate Lakes - Long Term 130 Ecological Research (NTL-LTER) program. These studies have documented some 131 significant ecological shifts that have occurred in the lake over the last $40 \mathrm{y}$ (Magnuson 132 et al. 2006). For example, establishment of rusty crayfish (Orconectes rusticus) in the 133 lake during the early 1980s decimated littoral macrophyte communities which resulted in 134 changes to the littoral food web (Lodge et al. 1986; Olden et al. 2006). To monitor these 135 ecological trends, NTL-LTER continually collects numerous ecological data on an 136 annual basis in Trout Lake, including data collect on pelagic fish assemblages from 137 vertical gillnetting and hydroacoustic surveys. However, no studies have examined 138 long-term dynamics of Trout Lake pelagic fishes, specifically its cisco population which 139 dominates the pelagic assemblage (Ahrenstorff et al. 2013).

\section{Fish and limnology datasets} Fisheries data were collected on Trout Lake and other NTL-LTER lakes annually 143 using a consistent methodology. In 2001, the NTL-LTER established modern 
144 standardized methods to collect and analyze hydroacoustic and vertical gillnet survey

145 data in lakes, to effectively monitor trends on the pelagic fish communities. This dataset

146 provided 15 years of available hydroacoustic data on cisco from Trout Lake, including

147 fish density estimates and single acoustic target data. Hydroacoustic data collection, 148 processing, and analyses followed methods described in Lawson et al. (2015) and the

149 general procedures outlined in Parker-Stetter et al. (2009). Annual hydroacoustic

150 surveys occurred during summer stratification at night and following systematic

151 transects covering pelagic portions of the lake (i.e., water depths $>6 \mathrm{~m}$ ). The amount of

152 hydroacoustic data needed for collection, reflecting the amount of transects, was

153 determined based on lake area and the spatial coverage necessary to achieve a CV =

$15425 \%$, as suggested by Aglen (1983). Additional details concerning sampling design and

155 collection settings can be accessed via pelagic prey sonar data and metadata on the

156 NTL-LTER website (https://lter.limnology.wisc.edu). From 2001-2003, hydroacoustics

157 data were collected using a Biosonics DT-6000 Echosounder with a $120 \mathrm{kHz}$ split beam

158 transducer; and from 2004-2015 with a Biosonics DT-X Echosounder with a $70 \mathrm{kHz}$ split

159 beam transducer. Data were collected consistently throughout the duration of the study

160 period using the same collection settings, including a pulse width of $0.04 \mathrm{~ms}$ and a ping

161 rate of $3 \mathrm{~s}^{-1}$. Survey data were processed and analyzed using Echoview software

162 (Myriax Pty Limited, Tasmania, Australia), where fish density (fish ha-1) was calculated

163 using echo integration and single echo detection using the same data processing

164 protocol and settings as Lawson et al. (2015). Cisco densities were estimated using 200

$165 \mathrm{~m}$ horizontal analysis bins. Single target data were produced by running single echo

166 detection algorithms in Echoview which only included individual targets larger than -55 
167 dB. Single target data were used to describe pelagic fish species composition. Further, 168 size distribution of all targets were estimated using Love's (1977) dorsal aspect 169 equation which allows conversion of target strength $(\mathrm{dB})$ to fish total length $(\mathrm{mm})$.

170 Each year in late summer (July-August), vertical gill nets were used to sample 171 pelagic fish populations throughout the entire water column. A series of seven 172 monofilament gill net panels, each being $4 \mathrm{~m}$ wide and $33 \mathrm{~m}$ long, were hung vertically 173 from foam rollers and chained together in a gang. The gangs of net panels were 174 arranged by graded mesh size $(19,25,32,38,51,64$, and $89 \mathrm{~mm})$, that were selected 175 to consistently capture a range of fish sizes (see Rudstam and Magnuson, 1984). All 176 nets were fished overnight for two consecutive $24 \mathrm{~h}$ periods (net night) at the deepest 177 location of the lake. Catches of all fish were recorded along with total lengths $(\mathrm{mm})$, 178 depth of capture from surface $(m)$, and a subset of fish were weighed. Catch per unit 179 effort (CPUE) was quantified as the total number of individuals sampled in the entire 180 gang of nets per net night (hereafter, referred to as fish net night ${ }^{-1}$. Vertical gillnet 181 CPUE was used an index of lake trout, lake whitefish and walleye relative abundance. 182 Additionally, gill net catch composition and size structure were used to ground-truth 183 hydroacoustics datasets (described in more detail below).

$184 \quad$ Various limnological and environmental parameters were also estimated.

185 Sampling protocols and raw data for all these parameters can be viewed and 186 downloaded from the NTL-LTER website (https://lter.limnology.wisc.edu). Parameters 187 examined in this study in relation to cisco production statistics included winter ice 188 duration, mean annual surface water temperature, rusty crayfish relative abundances, 189 mean annual zooplankton biovolume, mean annual pelagic macroinvertebrates 
190 biovolume, mean annual chlorophyll a, mean annual total phosphorus, and mean 191 annual total nitrogen. We calculated a minimum summer cisco habitat width as the 192 thickness of the oxythermal habitat between $3 \mathrm{mg} \cdot \mathrm{L}^{-1}$ dissolved oxygen from the bottom 193 to the point at which water temperatures exceeded $22.8^{\circ} \mathrm{C}$ or the surface. Finally, we 194 estimated maximum summer TDO3 (water temperature at a dissolved oxygen 195 concentration of $\left.3 \mathrm{mg} \cdot \mathrm{L}^{-1}\right)$. Minimum cisco habitat width and maximum TDO3 are 196 commonly used indices of oxythermal habitat in lakes (Jacobson et al. 2010).

\section{Production calculations}

199 Production estimations were made using the instantaneous growth method (Waters 200 1977), which summarizes production among cohorts (Dolbeth et al. 2012):

201 (1) $P_{t}=\sum G_{t, i} \bar{B}_{t, i}$

202 where $P$ is annual production $\left(\mathrm{kg} \mathrm{ha}^{-1} \mathrm{y}^{-1}\right), G$ represents the instantaneous annual 203 growth rate, calculated as

204

(2) $\quad G_{t, i}=\ln \left(\frac{\bar{W}_{t, i+1}}{\bar{W}_{t, i}}\right)$

$205 \bar{B}$ is mean standing stock biomass $\left(\mathrm{kg} \mathrm{ha}^{-1}\right), \bar{W}$ is mean weight $(\mathrm{kg}), i$ is age class, and $t$ 206 is the specific year corresponding to the data and estimates. For example, estimating $G$ 207 for age-1 fish in $2001\left(G_{2001,1}\right)$, would require mean weights of age-1 fish $\left(\bar{W}_{2001,1}\right)$ and 208 age-2 fish $\left(\bar{W}_{2001,2}\right)$ from 2001 to complete the calculation.

209 For this study, we used single target hydroacoustic data to estimate cisco size210 structure data, and ultimately age-structured biomass. However, single target data do

211 not have species assignments. Single fish target data describe where (latitude,

212 longitude, and depth) and when a target was detected during the survey, and the size of 
213 the target or target strength (decibels; converts to total length). Cisco population

214 characteristics were inferred from single target data based on vertical gillnet catches.

215 Specifically, we identified cisco targets using recursive partitioning or classification trees

216 built with the vertical gillnet data (Yule et al. 2013; Myers et al. 2015). Thus,

217 classification models were built for each annual gillnetting event and used to classify

218 species in hydroacoustic datasets collected at approximately the same time. In each

219 model, species classification was the response variable and the explanatory variables

220 were latitude, longitude, water column depth, capture depth (from surface), and total

221 length of fish. Because vertical gillnet efforts were focused on one location, latitude and

222 longitude were not used as explanatory variables in the models. Classifications were

223 built using the "rpart" package (Therneau and Atkinson 2012) in program R (R Core

224 Team 2014, version 3.1.2). Classification trees were built using a complexity parameter

$225(c p=0.0001)$ and then pruned to minimize cross-validation error related to splitting.

226 Lastly, we required a minimum of 10 fish per terminal node from pruned trees to be

227 included in the final trees. After classification trees were constructed using the vertical

228 gill net data, trees were applied to the single target data (including converted fish

229 lengths) to predict pelagic fish species composition and identify cisco-sized targets.

230 Cisco population data were then extracted from the predicted composition for

231 production calculations as described above.

232 Annual population estimates were converted to age-specific population values by

233 estimating the proportion of the population in different age classes (Rypel et al. 2015).

234 Length-at-age estimates were based on a recent survey of the cisco population in Trout

235 Lake by the Wisconsin Department of Natural Resources (WDNR unpublished data). 
236 For this survey, a subset of the cisco sampled with the vertical gill nets (5 individuals per

$23710 \mathrm{~mm}$ length bin) were retained for removal of otolith sagittae and age estimation.

238 Otolith sagittae were thin-sectioned using a low speed saw outfitted with a diamond

239 impregnated blade. Samples were polished using a series of progressively finer

240 sandpapers and viewed under a stereomicroscope using both transmitted and reflected

241 light. Ages were blindly estimated by three experienced readers and consensus ages

242 developed for any samples with disagreements between readers. A power regression

243 was created to predict cisco age based on total length in Trout Lake. This regression

244 was then used as a key to assign age estimates to all lengths of predicted cisco targets

245 from the hydroacoustic surveys as described above. Population estimates were then

246 converted to age-specific population estimates by multiplying the total population

247 estimate by the percentage of fish estimated in each age class for the population. Mean

248 mass-at-age was estimated for each year by applying a weight-length power regression

249 based on the NTL-LTER data for cisco in Trout Lake for the given average length in

250 each age class.

251 Annual production estimates were made using eq.1, and an example calculation

252 can be viewed in Table 1. Biomass by age class was calculated as the mathematical

253 product of the age-specific population estimate multiplied by the mean weight $(\bar{W})$ of

254 individuals in that age class $i$. Mean standing biomass $(\bar{B})$ was then calculated as the 255 average of the two biomass values between adjacent age-classes, which corresponds

256 to the same age-sequence when calculating instantaneous growth $(G)$ in eq. 2. Interval

257 production rates were calculated between adjacent year classes following eq.1. All age-

258 specific production estimates were then summed to gather an annual instantaneous 
259 production estimate for all cisco in Trout Lake for each year, 2001-2015. Similarly, all 260 age-specific biomass estimates were then summed to estimate an annual biomass for 261 all cisco in Trout Lake for each year, 2001-2015.

\section{Statistical analyses}

We developed frequency histograms for $\mathrm{P}, \mathrm{B}$ and $\mathrm{P} / \mathrm{B}$ to illustrate the distribution of production statistics for cisco in Trout Lake. Shapiro-Wilks tests were used to test for 266 normality in distributions of all three production statistics. Time series of $P, B$ and $P / B$ 267 were evaluated for serial correlation using Ljung-Box tests and correlograms, and then 268 assessed temporal trends using breakpoint regression analysis. Next, we evaluated the 269 proportional contributions to population $\mathrm{P}$ and $\mathrm{B}$ from sub-adult (ages $0-2$ ) and adult 270 (ages 3-older) cisco. We further assessed P and B contributions by separately

271 analyzing the coherence of $\mathrm{P}$ and $\mathrm{B}$ between total population and each contributing age 272 group. We then explored potential relationships between total P, B and P/B and the 14

273 limnological and ecological variables described above by developing linear multiple

274 regression models using a forward stepwise variable selection procedure. Prior to 275 variable selection, we removed all redundant variables $(r>0.5)$ to reduce collinearity. All 276 statistical analyses were performed in program $R$ ( $R$ Core Team 2014, version 3.1.2).

277 Production statistics and other variables were $\log 10$-transformed prior to all statistical

278 analyses to meet normality assumptions. Statistical significance was assessed with an $\alpha$ $279=0.05$. 
Classification trees developed using annual vertical gillnet catch characteristics

283 from 2001-2015 exhibited correct species classification rates ranging from 91-99\%

284 correct classification (Supplementary data 1). Species total length (mean variable

285 importance $=73)$ followed by species capture depth ( mean variable importance $=27$ )

286 were the most important predictors used for species classification of the vertical gillnet

287 catches. Once developed, trained classification trees assigned cisco to $96-99 \%$ of

288 acoustic fish targets (total SEDs ranged from 3599-34192). Similarly, cisco tended to

289 dominate vertical gillnet catches (mean $=84 \% ; 34-97 \%$ ) compared to other species.

290 Data from single echo detections classified as cisco (3540-34002 targets) were then

291 used to calculate production statistics.

292 Annual production statistics for cisco in Trout Lake were highly variable over

293 time. Biomass ranged 1.2-39.4 $\mathrm{kg} \mathrm{ha}^{-1}$ and production ranged 0.6-30.2 $\mathrm{kg} \mathrm{ha}^{-1} \mathrm{y}^{-1}$,

294 resulting in $\mathrm{P} / \mathrm{B}$ ratios ranging $0.4-0.9 \mathrm{y}^{-1}$ (Figure 1; Supplementary data 2). Production

295 and biomass values for cisco in Trout Lake followed non-normal distributions (all

296 Shapiro-Wilks tests P-values < 0.05), with distributions being composed mostly of low

297 values with periodic high values; whereas P/B values followed a normal distribution

298 (Shapiro-Wilks $\mathrm{P}=0.14$ ). Cisco production rates were largely comprised of sub-adult

299 cisco production contributions which represented 75\% (48-97\%; Figure 2) of total

300 production, whereas adult cisco only represented $25 \%$ (3-51\%). Sub-adult cisco

301 biomass represented $42 \%$ (15-85\%) of total biomass and adult cisco biomass

302 represented $58 \%(15-85 \%)$ to total biomass. There was strong coherence between total

303 production and sub-adult cisco production (Pearson's $r=0.99, P<0.0001$ ), yet total

304 production coherence with of adult cisco production was nearly half as strong $(r=0.51$, 
$305 P=0.05)$. Strong coherence occurred between both total biomass and sub-adult cisco 306 biomass $(r=0.88, P<0.0001)$ and adult biomass $(r=0.83, P<0.0001)$.

Time series of cisco production statistics revealed multiple temporal patterns.

308 Serial correlation was detected in total production $\left(X^{2}=8.84, P=0.03\right)$ and total

309 biomass $\left(X^{2}=6.19, P=0.01\right)$ time series, but not in $\mathrm{P} / \mathrm{B}\left(\mathrm{X}^{2}=0.98, P=0.32\right)$.

310 Breakpoint regression analysis identified a single breakpoint in 2011 (Figure 1)

311 describing a step change for cisco production and biomass trends $(P<0.01)$. The step

312 change was less strong for biomass $\left(R^{2}=0.46\right)$ than for production $\left(R^{2}=0.54\right)$, but was

313 still apparent. Specifically, cisco total production exhibited a negative temporal trend

314 (slope $=-0.33,95 \% \mathrm{Cl}:-0.53$ to -0.12$)$ before $2011(\mathrm{SE}=1.05)$, followed by a period of

315 no trend after 2011 (slope $=0.48,95 \% \mathrm{Cl}$ : -0.09 to 1.06 ). For biomass, we also

316 observed a break point in $2011(\mathrm{SE}=1.46)$ that separated a period of decline (slope $=-$

$3170.28,95 \% \mathrm{Cl}:-0.42$ to -0.13 ) from a period no trend (slope $=0.76,95 \% \mathrm{Cl}:-0.08$ to

318 1.60). No trends or apparent breakpoints were identified in the cisco P/B time series.

320 use in linear multiple regression models to explain production statistics. The cisco

321 production model selected lake trout CPUE, the cisco biomass model selected lake

322 trout CPUE and ice duration, and the P/B model selected pelagic macroinvertebrates

323 biovolume (Table 2). However, the only significant relationships were identified were

324 between lake trout CPUE and cisco production $\left(F=10.36, P=0.01, R^{2}=0.40\right)$ and

325 biomass $\left(F=6.80, P=0.01, R^{2}=0.45\right)$. Specifically, cisco production and biomass

326 were negatively associated with lake trout CPUE (Table 2, Figure 3). Annual cisco P/B

327 showed no significant relationship with any ecological variable (Table 2; $F=2.34, P=$ 
$\left.3280.15, R^{2}=0.09\right)$. With the exception of cisco production, few of the other ecological

329 factors examined changed over the study period (Supplementary data 3).

\section{Discussion}

We found that production of cisco in Trout Lake exhibited considerable decline

334 until 2011. Currently, the cisco production appears to be at its lowest state, a trend that

335 has occurred despite no change in the quality or quantity of cisco habitat in the lake.

336 P/B has also not changed, indicating the productive capacity of the population remains

337 intact. Cisco biomass and production values were inversely related to annual estimates

338 of lake trout abundance, and lake trout have only increased with time, coincident with

339 stocking. This exogenous factor highlights a potentially important predator-prey

340 relationship, and demonstrates how management of apex predators can significantly

341 influence fish production rates at lower trophic levels.

\section{Cisco production dynamics in Trout Lake}

Fish production dynamics can hinge strongly on geographic location. For example, cisco populations show a positive geometric relationship between production

347 and latitude (Rypel and David 2017). Thus, production of cisco in a range-wide context

348 tends to be highest in northern lakes that are colder, and reduced in southern lakes that

349 are warmer. Using the production estimates reported for 23 cisco populations in Rypel 350 and David (2017), Trout Lake production ranked in the 36th percentile relative to the 
351 other reported populations. Lake Winnipeg, Manitoba, Canada regularly had production 352 estimates exceeding $100 \mathrm{~kg} \cdot \mathrm{ha}^{-1} \cdot \mathrm{y}^{-1}$, and had the highest estimated value (1204 $\mathrm{kg} \cdot \mathrm{ha}^{-}$ $\left.353{ }^{1} \cdot y^{-1}\right)$. In contrast, Mille Lacs Lake, Minnesota, USA exhibited some of the lowest cisco 354 production estimates, with all estimates $<0.6 \mathrm{~kg} \cdot \mathrm{ha}^{-1} \cdot \mathrm{y}^{-1}$, and many years approaching 0 $355 \mathrm{~kg} \cdot \mathrm{ha}^{-1} \cdot \mathrm{y}^{-1}$. Therefore, cisco in Trout Lake represent a relatively productive population 356 for the southern portion of the cisco range. However, this level of production is 357 comparatively low relative to cisco populations farther north. Production and biomass estimates were right-skewed and log-normal in 359 distribution, and this finding has important management implications. For example, low 360 production years were common and high production years were rare. This finding is 361 identical to a recent study that quantified production rates of walleye populations 362 spatially (Rypel et al. 2017) in addition to long-term production studies of the species 363 within a single ecosystem (Rypel et al. 2015). Furthermore, the contribution of sub-adult 364 (ages 0-2) cisco production drives total annual production variations. Therefore, fish 365 production might appear low or in a state of decline, but periodic high recruitment buoys 366 the population over periods of lower production. Future research should explore the 367 extent to which temporal heterogeneity in production differs between healthy and failing 368 populations. More specifically, early indicators might be developed (e.g., Carpenter et 369 al. 2011; Seekell et al. 2011) to identify fragile fisheries based on production and 370 temporal heterogeneity in production.

371 The mechanisms responsible for the decline in cisco production in Trout Lake

372 during this study period appeared to more biotic than abiotic, since decline was primarily 373 related to increased lake trout abundance. Lake trout and cisco have very specific 
374 oxythermal habitat constraints, particularly lake trout, which are much more sensitive to

375 habitat perturbations than cisco (Jacobson et al. 2010). The continued persistence of

376 sensitive lake trout in Trout Lake implies that the decline of cisco be less likely due to

377 abiotic factors like habitat degradation. Additionally, it is much more likely that lake trout

378 were interacting with cisco in Trout Lake, due to their specific oxythermal habitat

379 constraints (Jacobsen et al.2010) and habitat segregation (Kerr and Grant 2000), thus,

380 limiting much of the predation pressures from other warm-water predator species, in

381 Trout Lake. In Trout Lake, lake trout were observed to be mainly piscivorous and

382 primarily selecting cisco over other prey items (Couey 1935). When available, cisco are

383 considered to be the principle prey item for many other North American lake trout

384 populations (Hacker 1957; Dryer et al. 1965; Martin and Oliver 1980; Matuszek et al.

385 1990; Kerr and Grant 2000). Based on the results of our study and work from

386 Ahrenstorff et al. (2013), the numerically dominant species in Trout Lake were cisco and

387 therefore, likely the best candidate for being consumed by lake trout. Numerous

388 linkages have been identified between artificial increases in lake trout and reduced

389 cisco populations (Kerr and Grant 2000). For instance, following the stocking and

390 subsequent abundance increases in stocked lake trout in Lake Simcoe, Ontario, the

391 prey community, including cisco exhibited substantial decline (Evans and Waring,

392 1987). Based on lake trout prey selection, the availability of cisco, and the intensive lake

393 trout stocking history in Trout Lake, it remains most plausible that increases in lake trout

394 have led to increasing predation on cisco.

395 Importantly, while cisco production and biomass responded negatively to

396 increasing lake trout abundance, $\mathrm{P} / \mathrm{B}$ ratios of the cisco population have remained 
397 unchanged. Thus, the overall productive capacity of the cisco population remains 398 strong, even though production and biomass were reduced. Interestingly, Rypel et al. 399 (2015) presented a similar finding using a walleye population in a nearby lake 400 (Escanaba Lake, Vilas County, WI USA); P/B ratios for walleye remained stable over 401 time despite large changes in angler exploitation. Thus, although walleye production 402 and biomass exhibited declines at high rates of exploitation, the productive capacity 403 remained unchanged; meaning walleye biomass would take the same amount of time to 404 develop. In our study, invariance of cisco P/B is an important finding. For example, this 405 population is predicted to have a fast recovery potential should lake trout abundances 406 be reduced (e.g., through reduced stocking or increased harvest of lake trout).

$407 \quad$ Fisheries managers are often geared towards single management approaches 408 even though ecosystem-based approaches are usually beneficial (Link 2002; Pikitch et 409 al. 2004; Walters et al. 2005). An inability to account for predator-prey dynamics can 410 lead to fishery collapse should biomass of predators exceed the capacity of prey

411 populations to supply energy to this trophic level (e.g., Kao et al. 2016). Stocking efforts 412 to maintain and increase native lake trout in Trout Lake have been successful over time 413 (Jahns and Bozek 2000), but may have unintended negative consequences for cisco.

414 Trout Lake is only one of two known genetically-unique, naturally reproducing lake trout 415 populations in Wisconsin (Piller et al. 2005). Based on our results, we suggest that

416 fisheries managers evaluate and adjust lake trout stocking rates in Trout Lake, to further 417 investigate and improve predator-prey balance and pro-actively minimize the risk of 418 potential fishery collapse. 
Secondary production estimates can be sensitive of the method of production

420 estimation (Waters 1977). Furthermore, there are assumptions and biases in all

421 methods of production estimation (Dolbeth et al. 2012). For the instantaneous growth

422 method, it is worth differentiating this form of production estimation (i.e., a "snapshot"

423 method) from other methodologies since it makes a pseudo-cohort assumption. Other

424 methods attempt to empirically track gains and losses of biomass of particular cohorts

425 over time (e.g., the increment summation method; Waters 1977). In the instantaneous

426 growth method, recruitment dynamics across all age classes are integrated into the

427 annual production estimate; thus, the annual production estimates synthesize more

428 ecological information than what occurs during just one calendar year (Myers et al.

429 2017). Yet in cases where production is strongly driven by annual recruitment dynamics

430 (i.e., age-0 abundances), the instantaneous growth method likely represents true

431 biomass production. It is possible that production estimates could be developed for

432 cisco and other pelagic fish populations in lakes using other (cohort) methods of

433 production estimation. To this end, hydroacoustics data would need to be collected with

434 a higher sampling intensity (e.g., monthly), and these topics ultimately remain beyond

435 the scope of this research. Lastly, our empirical estimation of production statistics

436 maybe somewhat influenced by the limited amount of age and growth information

437 collected throughout the entire duration of the study period. Regardless, the high-

438 resolution hydroacoustic fish density and size-structure data allowed us to identify

439 strong patterns in age-specific fish densities, particularly for younger fish of which tends

440 to drive total production estimates more than growth (see Rypel et al. 2015).

441 Fortunately, we were able to compare our cisco growth data with historical growth data 
442 from Trout Lake from Rudstam (1984) which we found to be statistically comparable to

443 ours, so we assumed that age - specific growth (i.e., mean size at age) was relatively

444 stable over time. Nonetheless, we acknowledged and accepted the caveat that inter-

445 annual growth variations represented a potential source of error that we were not able

446 to control or completely understand.

$447 \quad$ Understanding production dynamics is one of the foundational themes in

448 fisheries science (Smith and Swingle 1938; Ricker 1946; Rawson 1952). Yet despite

449 widespread recognition, empirical evaluations of fish production have generally

450 declined. For some time, it was commonly thought that the effort, data and cost needed

451 to estimate fish production was simply too high to warrant broader use. Yet in reality, all

452 the data needed to empirically estimate fish production are already collected in many

453 high-profile fisheries. Thus ironically, many fisheries are managed using all the

454 component pieces of production (i.e., growth, density, size) without ever evaluating

455 production directly. New tools like hydroacoustics may be increasing the ability and

456 reducing the cost of making direct fish production estimates. Furthermore, the Canadian

457 Fisheries Act was recently amended to reflect an overall goal of providing for the

458 sustainability and ongoing productivity of commercial, recreational and Aboriginal

459 fisheries. Thus, new tools and approaches for quantifying fisheries production should

460 have broad appeal, especially for Canadian inland lakes, where food webs are largely

461 based on coregonids (Coregonus spp.). To our knowledge, this paper provides one of

462 the first applications of hydroacoustics for the estimation of secondary production rates

463 in North American inland fisheries. We encourage other researchers to explore

464 empirical production rates as a tool for understanding inland fisheries more dynamically. 
466 Acknowledgements

467

468 We thank a large number of students and biologists, too many to individually name, that

469 assisted in the collection of NTL-LTER data. Tom Hrabik provided helpful discussions of

470 the NTL-LTER hydroacoustics data. We also thank WDNR scientists Greg Sass, Dan

471 Walchak, Justin Haglund, Aaron Nolan, and John Lyons for cisco age and growth data

472 from Trout Lake. Steve Gilbert, Jake Vander Zanden, John Lyons, K. Martin Perales,

473 Jake Walsh, Timothy Simonson, Lori Tate, Justine Hasz, Scott Toshner, Joanna Griffin,

474 Steve Hewitt, Greg Sass, Madeline Magee, David Boyarski, Joe Gerbyshak, Tyler

475 Tunney and two anonymous reviewers provided reviews on earlier iterations of this

476 work. Financial support for this study was provided by the Wisconsin Department of

477 Natural Resources, Office of Applied Sciences, Federal Aid in Sport Fish Restoration

478 (Project F-95-P, study SSSO) and by the National Science Foundation under

479 Cooperative Agreement \#DEB-1440297, NTL-LTER.

480 
481

482

483

484

485

486

487

488

489

490

491

492

493

494

495

496

497

498

499

500

501

502

503

97

\section{References}

Aglen, A. 1983. Random errors of acoustic fish abundance estimates in relation to the survey grid density applied. FAO Fish Rep 300: 293-297.

Ahrenstorff, T.D., Hrabik T.R., Jacobson, P.C., and Pereira, D.L. 2013. Food resource effects on diel movements and body size of cisco (Coregonus artedi) in northtemperate lakes. Oecologia 173: 1309-1320.

Carpenter, S.R., Cole, J.J., Pace, M.L., Batt, R., Brock, W.A., Cline, T., Coloso, J., Hodgson, J.R., Kitchell, J.F., Seekell, D.A., Smith, L., and Weidel, B. 2011. Early warning indicators of regime shifts: A whole ecosystem experiment. Science 332: 1079-1082.

Charnov, E.L. 1993. Life history invariants. Oxford University Press, Oxford.

Christensen, V., and Walters, C.J. 2004. Ecopath with Ecosim: methods, capabilities and limitations. Ecol. Model. 172: 109-139.

Colvin, M.E., Pierce, C.L., Stewart, T.W., and Grummer, S.E. 2012. Strategies to control a common carp population by pulsed commercial harvest. N. Am. J. Fish. Manage. 32: 1251-1264. 
504 Couey, F.M. 1935. Fish food studies in a number of northeastern Wisconsin Lake.

$505 \quad$ Trans. Wisc. Acad. Sci. Arts. Lett. 19: 131-172.

506

507 Cox, S.P., and Kitchell, J.F. 2004. Lake Superior ecosystem, 1929-1998: simulating

508 alternative hypotheses for recruitment failure of lake herring (Coregonus artedi).

509 Bull. Mar. Sci. 74(3): 671-683.

510

511 Dolbeth, M., Cusson, M., Sousa, R., and Pardal, M.A. 2012. Secondary production as a 512 tool for better understanding of aquatic ecosystems. Can. J. Fish. Aquat. Sci. 69(7): 1230-1253. doi:10.1139/f2012-050.

514

515 Dryer, W.R., Erkkila, L.F., and Tetzloff, C.L. 1965. Food of lake trout in Lake Superior.

$516 \quad$ Trans. Am. Fish. Soc. 94(2): 169-176.

517

518 Ebener, M.P. 1995. Bioenergetics of predatory fish in western U.S. waters of Lake 519 Superior, Bayfield, Wisconsin: Report prepared for the Red Cliff Band of Lake $520 \quad$ Superior Chippewas.

521

522 Evans, D.O., and Waring, P. 1987. Changes in the Multispecies, Winter Angling Fishery 523 of Lake Simcoe, Ontario, 1961-83: invasion by rainbow smelt, Osmerus mordax, 524 and the roles of intra- and interspecific interactions. Can. J. Fish. Aquat. Sci. 44:

$525 \quad$ 182-197.


527 Fabrizio, M.C., Adams, J.V., and Curtis, G.L. 1997. Assessing prey fish populations in 528 Lake Michigan: comparison of simultaneous acoustic-midwater trawling with 529 bottom trawling. Fish. Res. 33: 37-54.

530

531 Fang, X., Jiang, L., Jacobson, P.C., Stefan, H.G., Alam, S.R., and Pereira, D.L. 2012. 532 Identifying cisco refuge lakes in Minnesota under future climate scenarios. Trans. Am. Fish. Soc. 141(6): 1608-1621.

535 Hansen, M.J., Boisclair, D., Brandt, S.B., Hewett, S.W., Kitchell, J.F., Lucas, M.C., and Ney, J.J. 1993. Applications of bioenergetics models to fish ecology and management: where do we go from here? Trans. Amer. Fish. Soc. 122: 1019-

543

544 Honsey, A.E., Donabauer, S.B., and Höök, T.O. 2016. An analysis of lake morphometric 545 1030.

Henderson, B.A., Morgan, G.E. and Vaillancourt, A. 2004. Growth, ingestion rates and metabolic activity of walleye in lakes with and without lake herring. J. Fish Biol. and land-use characteristics that promote persistence of cisco in Indiana. Trans.

547

548 Hrabik, T., Schreiner, D., Balge, M., and Geving, S. 2006. Development of a hydroacoustic sampling design to quantify prey fish abundance in the Minnesota 
waters of Lake Superior. Minnesota Department of Natural Resources

551 Investigational Report 530, St. Paul.

552

553 Jacobson, P.C. 1992. Analysis of factors affecting growth of northern pike in Minnesota.

554 Minnesota Department of Natural Resources Investigational Report 424, St.

$555 \quad$ Paul.

556

557 Jacobson, P.C., Jones, T.S., Rivers, P., and Pereira, D.L. 2008. Field estimation of a 558 lethal oxythermal niche boundary for adult cisco in Minnesota lakes. Trans. Am. Fish. Soc. 137(5): 1464-1474. doi:10.1577/T07-148.1.

560

561 Jacobson, P.C., Stefan, H.G., and Pereira, D.L. 2010. Coldwater fish oxythermal habitat 562 in Minnesota lakes: influence of total phosphorus, July air temperature, and 563 relative depth. Can. J. Fish. Aquat. Sci. 67(12): 2002-2013.

564

565 Jahns, W., and Bozek, M. 2000. Upper Wisconsin Basin inland lake trout management 566 plan. Wisconsin Department of Natural Resources Report, Madison.

567

568 Jiang, L., Fang, X., Stefan, H.G., Jacobson, P.C., and Pereira, D.L. 2012. Oxythermal 569 habitat parameters and identifying cisco refuge lakes in Minnesota under future $570 \quad$ climate scenarios using variable benchmark periods. Ecol. Modell. 232: 14-27. 
572 Kao, Y.C., Adlerstein, S.A., and Rutherford, E.S. 2016. Assessment of top-down and 573 bottom-up controls on the collapse of alewives (Alosa pseudoharengus) in Lake $574 \quad$ Huron. Ecosystems 19: 803-831.

575

576 Kaufman, S.D., Morgan, G.E., and Gunn, J.M. 2009. The role of ciscoes as prey in the trophy growth potential of walleyes, N. Am. J. Fish. Manag. 29 (2): 468-477. DOI: 10.1577/M07-117.1.

579

580 Kerr, S.J., and Grant, R.E. 2000. Ecological impacts of fish introductions: evaluation of 581 risks. Fish and Wildlife Branch Report, Ontario Ministry of Natural Resources, Peterborough, Ontario.

583

584 Kwak, T.J., and Waters, T.F. 1997. Trout production dynamics and water quality in 585 Minnesota streams. Trans. Am. Fish. Soc. 126: 35-48.

586

587 Lathrop, R.C., Johnson, B.M., Johnson, T.B., Vogelsang, M.T., Carpenter, S.R., Hrabik, 588 T.R., Kitchell, J.F., Magnuson, J.J., Rudstam, L.G., and Stewart, R.S. 2002. 589 Stocking piscivores to improve fishing and water clarity: a synthesis of the Lake $590 \quad$ Mendota biomanipulation project. Freshwater Biol. 47: 2410-2424. doi: 10.1046/j.1365-2427.2002.01011.x.

592

593 Lawson, Z.J., Vander Zanden, M.J., Smith, C.A., Heald, E., Hrabik, T.R., Carpenter, 594 S.R., and Rosenfeld, J. 2015. Experimental mixing of a north-temperate lake: 
Testing the thermal limits of a cold-water invasive fish. Can. J. Fish. Aquat. Sci. 72: 926-937. doi: 10.1139/cjfas-2014-0346.

597

598 Link, J.S. 2002. What does ecosystem-based fisheries management mean. Fisheries 599 27: 18-21.

600

601 Lobón-Cerviá, J., Gonzáles, G., and Budy, P. 2011. Factors driving spatial and temporal variation in production and production/biomass ratio of stream resident brown

603 trout (Salmo trutta) in Cantabrian streams. Freshwater Biol. 56: 2040-2055.

604

605 Lodge, D.M., Kratz, T.K., and Capelli, G.M. 1986. Long-term dynamics of three crayfish species in Trout Lake, Wisconsin. Can. J. Fish. Aquat. Sci. 43: 993-998.

607

608 Love, R.H. 1977. Target strength of an individual fish at any aspect. J. Acoust. Soc. Am.

609 62: $1397-1403$.

610

611 Magnuson, J.J., Kratz, T.K., and Benson, B.J. 2006. Long-term dynamics of lakes in the landscape. Oxford University Press, Inc., New York.

613

614 Martin, N.V. and Oliver, C.H. 1980. The lake charr. Salvelinus namaycush. p. 205-277

615 In Balon, E.K., editor. Charrs, salmonid fishes of the genus Salvelinus. W. Junk, 616 The Hague, Netherlands. 
618 Mason, D.M., Johnson, T.B., Harvey, C.S., Kitchell, J.F., Schram, S.T., Bronte, C.R., 619 Hoff, M.H., Lozano, S.J., Trebitz, A.S., Schreiner, D.R., Lamon, E.C., and Hrabik, T. 2005. Hydroacoustic estimates of abundance and spatial distribution of pelagic prey fishes in western Lake Superior. J. Great Lakes Res. 31: 426-438.

622

623 Matuszek, J.E., Shuter, B.J., and Casselman, J.M. 1990. Changes in lake trout growth 624 and abundance after introduction of cisco into Lake Opeongo, Ontario. Trans. Am. Fish. Soc. 119(4): 718-729.

626

627 Milne, S.W., Shuter, B.J., and Sprules, W.G. 2005. The schooling and foraging ecology 628 of lake herring (Coregonus artedi) in Lake Opeongo, Ontario, Canada. Can. J. Fish. and Aquat. Sci. 62: 1210-1218.

630

Myers, B.J.E., Dolloff, C.A., Webster, J.R., Nislow, K.H., Fair, B., and Rypel, A.L. 2017. Fish assemblage production estimates in Appalachian streams across a latitudinal and temperature gradient. Ecol. Freshw. Fish. In Press.

635 Myers, J.T., Yule, D.L., Jones, M.L., Ahrenstorff, T.D., Hrabik, T.R., Claramunt, R.M., Ebener, M.P., and Berglund, E.K. 2015. Spatial synchrony in cisco recruitment. Fish. Res. 165: 11-21.

638

639 Olden, J.D., McCarthy, J.M., Maxted, J.T., Fetzer, W.W., and Vander Zanden, M.J. 2006. The rapid spread of rusty crayfish (Orconectes rusticus) with observations 
on native crayfish declines in Wisconsin (U.S.A.) over the past 130 years. Biol.

642 Invasions, 8(8): 1621-1628. doi:10.1007/s10530-005-7854-2.

643

644 Parker-Stetter, S.L., Rudstam, L.G., Sullivan, P.J., and Warner, D.M. 2009. Standard 645 operating procedures for fisheries acoustic surveys in the Great Lakes. Great Lakes Fishery Commission Special Publication, Michigan.

647

648 Pikitch, E.K., Santora, C., Babcock, E.A., Bakun, A., Bonfil, R., Conover, D.O., Dayton,

649 P., Doukakis, P., Fluharty, D., Heneman, B., Houde, E.D., Link, J., Livingston, P.A., Mangel, M., McAllister, M.K., Pope, J., and Sainsbury, K.J. 2004. Ecosystem-based fishery management. Science 305: 346-347.

652

653 Piller, K. R., C. C. Wilson, C. E. Lee, and J. Lyons. 2005. Conservation genetics of inland lake trout in the upper Mississippi Basin: stocked or native ancestry. T. Am. Fish. Soc. 134: 789-802.

656

657 Randall, R., and Minns, C. 2000. Use of fish production per unit biomass ratios for measuring the productive capacity of fish habitats. Can. J. Fish. Aquat. Sci. 57:

660

661 Rawson, D.S. 1952. Mean depth and the fish production of large lakes. Ecology 33:

662 513-521.

663 
664 Ricker, W.E. 1946. Production and utilization of fish populations. Ecol. Monogr. 16:

$665 \quad 373-391$.

666

667 Rudstam, L.G. 1984. Long term comparison of the population structure of the cisco

668 (Coregonus artedi Le Sueur) in smaller lakes. Trans. Wisc. Acad. Sci Arts Lett. 72:

669 185-200.

670

671 Rudstam, L.G., Magnuson, J.J., and Tonn, W.M. 1984. Size selectivity of passive 672 fishing gear: a correction for encounter probability applied to gill nets. Can. J.

673 Fish. Aquat. Sci. 41(8): 1252-1255.

674

675 Rudstam, L.G., Lathrop, R.C., and Carpenter, S.R. 1993. The rise and fall of a dominant 676 planktivore: direct and indirect effects on zooplankton. Ecology 74: 303-319.

677

678 Rypel, A.L., Goto, D., Sass, G.G., and Vander Zanden, M.J. 2015. Production rates of 679 walleye and their relationship to exploitation in Escanaba Lake, Wisconsin, 680 1965-2009. Can. J. Fish. Aquat. Sci. 72: 834-844.

681

682 Rypel, A.L., and David, S.R. 2017. Pattern and scale in latitude-production relationships 683 for freshwater fishes. Ecosphere 8(1): e01660. DOI: 10.1002/ecs2.1660. 
685 Rypel, A.L., Goto, D., Sass, G.G., and Vander Zanden, M.J. 2017. Eroding productivity 686 of walleye populations in northern Wisconsin lakes. Can. J. Fish. Aquat. Sci. In $687 \quad$ Review.

688

689 Scott, W.B., and Crossman, E.J. 1973. Freshwater fishes of Canada. Bull. Fish. Res. $690 \quad$ Board Can. No. 184.

691

692 Seekell, D.A., Carpenter, S.R., and Pace, M.L. 2011. Conditional heteroscedasticity as 693 a leading indicator of ecological regime shifts. Am. Nat. 178: 442-451.

694

695 Shulz, M., Koschel, R., Reese, C., and Mehner, T. 2004. Pelagic trophic transfer 696 efficiency in an oligotrophic, dimictic deep lake (Lake Stechlin, Germany) and its relation to fisheries yield. Limnologica 34(3): 264-273.

698

699

700

Smith, E.V., and Swingle, H.S., 1938. The relationship between plankton production and 701

702 Stein, R.A., DeVries, D.R., and Dettmers, J.M. 1995. Food-web regulation by a 703

704 planktivore: exploring the generality of the trophic cascade hypothesis. Can. J.

705

706 Stewart, D.J., Kitchell, J.F., and Crowder, L.B. 1981. Forage fishes and their salmonid 707 predators in Lake Michigan. Trans. Am. Fish. Soc. 110(6): 751-763. 
709 Therneau, T.M., and Atkinson, B. 2012. rpart: Recursive Partitioning. R port by B.

$710 \quad$ Ripley. R package version 3.1-55.

711

712 Tsehaye, I., Jones, M.L., Bence, J.R., Brenden, T.O., Madenjian, C.P., and Warner,

713 D.M. 2014. A multispecies statistical age-structured model to assess predator-

714 prey balance: application to an intensively managed Lake Michigan pelagic fish

715 community. Can. J. Fish. Aquat. Sci. 71(4): 627-644. doi:10.1139/cjfas-2013-

$716 \quad 0313$.

717

718 Tunney, T.D., McCann, K.S., Lester, N.P., and Shuter, B.J. 2014. Effects of differential 719 habitat warming on complex communities. Proc. Nat. Acad. Sci. 111(22): 8077$720 \quad 8082$.

721

722 Valentine-Rose, L., Layman, C., Arrington, D., and Rypel, A. 2007. Habitat

723 fragmentation decreases fish secondary production in Bahamian tidal creeks.

$724 \quad$ Bull. Mar. Sci. 80: 863-877.

725

726 Vander Zanden, M.J., and Vadeboncoeur, Y. 2002. Fishes as integrators of benthic and 727 pelagic food webs in lakes. Ecology 83: 2152-2161.

728 
729 Vanni, M.J., Luecke, C., Kitchell, J.F. and Magnuson, J.J. 1990. Effects of planktivorous

730 fish mass mortality on the plankton community of Lake Mendota, Wisconsin:

731 implications for biomanipulation. Hydrobiologia 200/201: 329-336.

732

733 Waters, T.F. 1977. Secondary production in inland waters. Adv. Ecol. Res. 10: 91-164.

734

735 Waters, T.F. 1992. Annual production, production/biomass ratio, and the ecotrophic

$736 \quad$ coefficient for management of trout in streams. N. Am. J. Fish. Manage. 12: 34-

$737 \quad 39$.

738

739 Walters, C.J., Christensen, V., Martell, S.J., and Kitchell, J.F. 2005. Possible ecosystem 740 impacts of applying MSY policies from single-species assessment. ICES J. Mar.

$741 \quad$ Sci. $62:$ 558-568.

742

743 Yule, D.L., Adams, J.V., Hrabik, T.R., Vinson, M.R., Woiak, Z., and Ahrenstorff, T.D.

744 2013. Use of classification trees to apportion single echo detections to species:

$745 \quad$ application to the pelagic fish community of Lake Superior. Fish. Res. 140: 123-

746132. 
747 Figure Legends

748

749 Figure 1.- Long-term trends in production, biomass and P/B of cisco (Coregonus artedi)

750 from Trout Lake, Wisconsin, 2001-2015. Inset time series of log-transformed cisco

751 production statistics show where significant $(P \leq 0.05)$ breakpoint regressions were

752 identified.

753

754 Figure 2.- Long-term trends in sub-adult (0-2), adult (3-older), and total production and

755 biomass of cisco (Coregonus artedi) from Trout Lake, Wisconsin, 2001-2015.

756

757 Figure 3.- Example relationships between lake trout (Salvelinus namaycush) catch-per-

758 unit-effort in vertical gill nets and cisco (Coregonus artedi) production and biomass.

759 Pearson correlation significance and coefficients for each comparison are noted as text 760 in the upper right corner of each panel. 
1 Table 1. Example calculation of cisco (Coregonus artedi) secondary production in Trout Lake, Wisconsin USA, for one

2 calendar year (2014). $B=$ total annual biomass, $\bar{B}=$ mean biomass between age classes, $G=$ instantaneous growth rate,

3 and $P=$ production rate.

\begin{tabular}{cccccccc}
\hline Age & Number & Total weight $\mathbf{( k g )}$ & Mean Weight $\mathbf{k g})$ & $\boldsymbol{B}\left(\mathbf{k g} \cdot \mathbf{h a} \mathbf{H}^{-1}\right)$ & $\overline{\boldsymbol{B}} \mathbf{( \mathbf { k g } \cdot \mathbf { h a } ^ { - 1 } )}$ & $\boldsymbol{G}$ & $\boldsymbol{P}\left(\mathbf{k g} \cdot \mathbf{h a}^{-1} \cdot \mathbf{y}^{-1}\right)$ \\
\hline 0 & 3682559 & 10137 & 0.003 & 6.48 & & & \\
1 & 40930 & 1112 & 0.027 & 0.71 & 3.60 & 2.29 & 8.24 \\
2 & 79522 & 2578 & 0.032 & 1.65 & 1.18 & 0.18 & 0.21 \\
3 & 53794 & 2271 & 0.042 & 1.45 & 1.55 & 0.26 & 0.41 \\
4 & 47947 & 2574 & 0.054 & 1.65 & 1.55 & 0.24 & 0.37 \\
5 & 38591 & 2691 & 0.070 & 1.72 & 1.68 & 0.26 & 0.44 \\
6 & 40930 & 3605 & 0.088 & 2.31 & 2.01 & 0.23 & 0.47 \\
7 & 51455 & 5968 & 0.116 & 3.82 & 3.06 & 0.28 & 0.84 \\
8 & 43269 & 6428 & 0.149 & 4.11 & 3.96 & 0.25 & 0.98 \\
9 & 28066 & 5338 & 0.190 & 3.41 & 3.76 & 0.25 & 0.93 \\
10 & 32744 & 8088 & 0.247 & 5.17 & 4.29 & 0.26 & 1.12 \\
Totals & 4139809 & & & 33.50 & & & $\mathbf{1 4 . 0 2}$ \\
\hline
\end{tabular}


5 Table 2. Results of stepwise variable selection for linear multiple regression models of cisco production statistics. Model 6 output in log-10 transformation for model interpretation.

\begin{tabular}{|c|c|c|c|c|c|c|}
\hline Model & Variable & Coefficient & $\mathrm{SE}$ & $P$ & $F$ & $\begin{array}{r}\text { Adjusted } \\
R^{2}\end{array}$ \\
\hline \multirow{2}{*}{$\begin{array}{l}\text { Cisco } \\
\text { production }\end{array}$} & Intercept & 1.31 & 0.19 & $<0.01$ & \multirow[t]{2}{*}{10.36} & \multirow[t]{2}{*}{0.40} \\
\hline & Lake trout CPUE & -0.92 & 0.29 & 0.01 & & \\
\hline \multirow{3}{*}{$\begin{array}{l}\text { Cisco } \\
\text { biomass }\end{array}$} & Intercept & -2.49 & 2.63 & 0.36 & \multirow[t]{3}{*}{6.80} & \multirow[t]{3}{*}{0.45} \\
\hline & Lake trout CPUE & -0.79 & 0.26 & 0.01 & & \\
\hline & Ice duration & 1.90 & 1.53 & 0.15 & & \\
\hline Cisco & Intercept & 0.39 & 0.43 & 0.37 & \multirow[t]{2}{*}{2.34} & \multirow[t]{2}{*}{0.09} \\
\hline $\mathrm{P} / \mathrm{B}$ & $\begin{array}{l}\text { Pelagic macroinvertebrates } \\
\text { biovolume }\end{array}$ & -0.18 & 0.11 & 0.15 & & \\
\hline
\end{tabular}


Figure 1.-

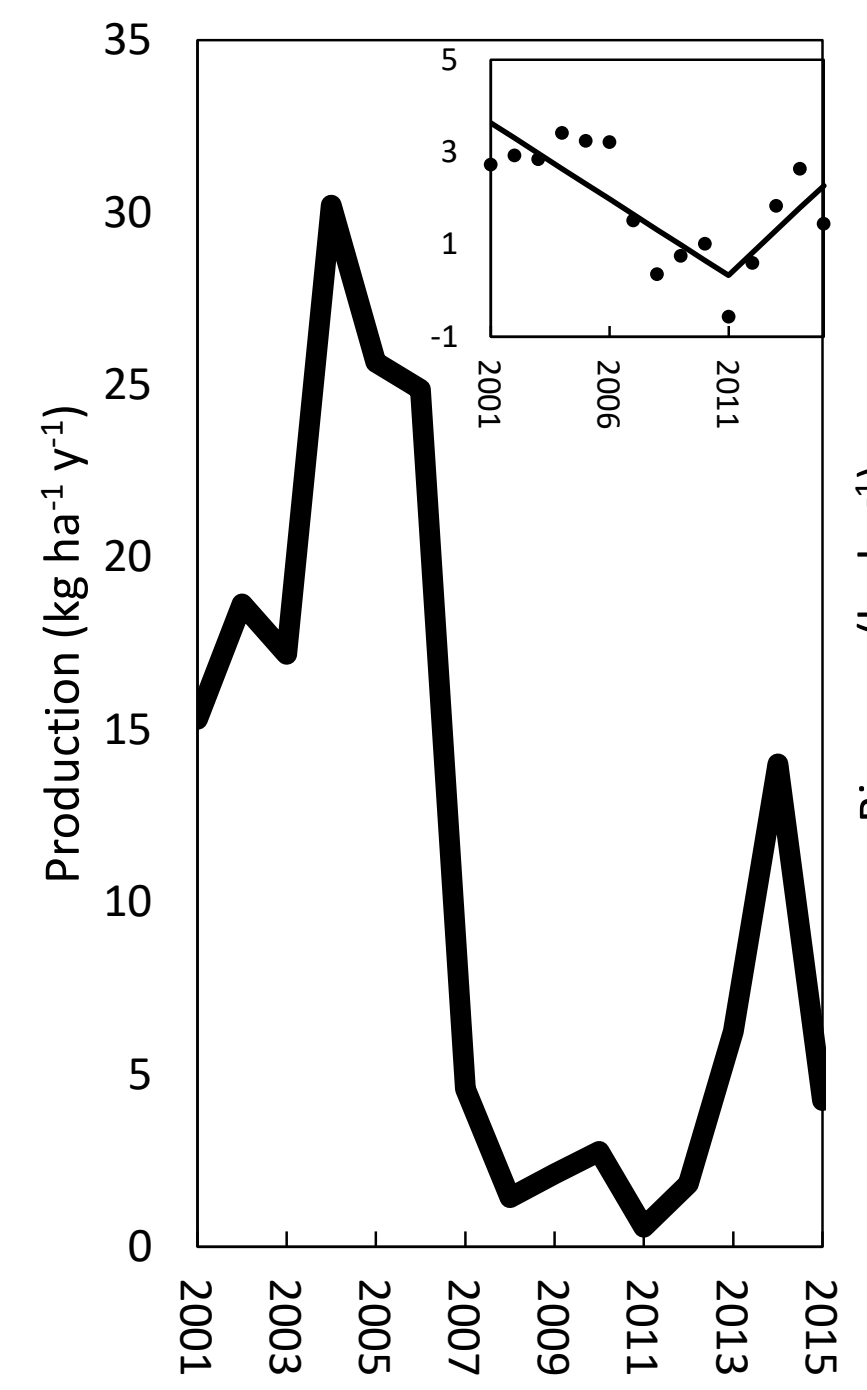

Page 38 of 40
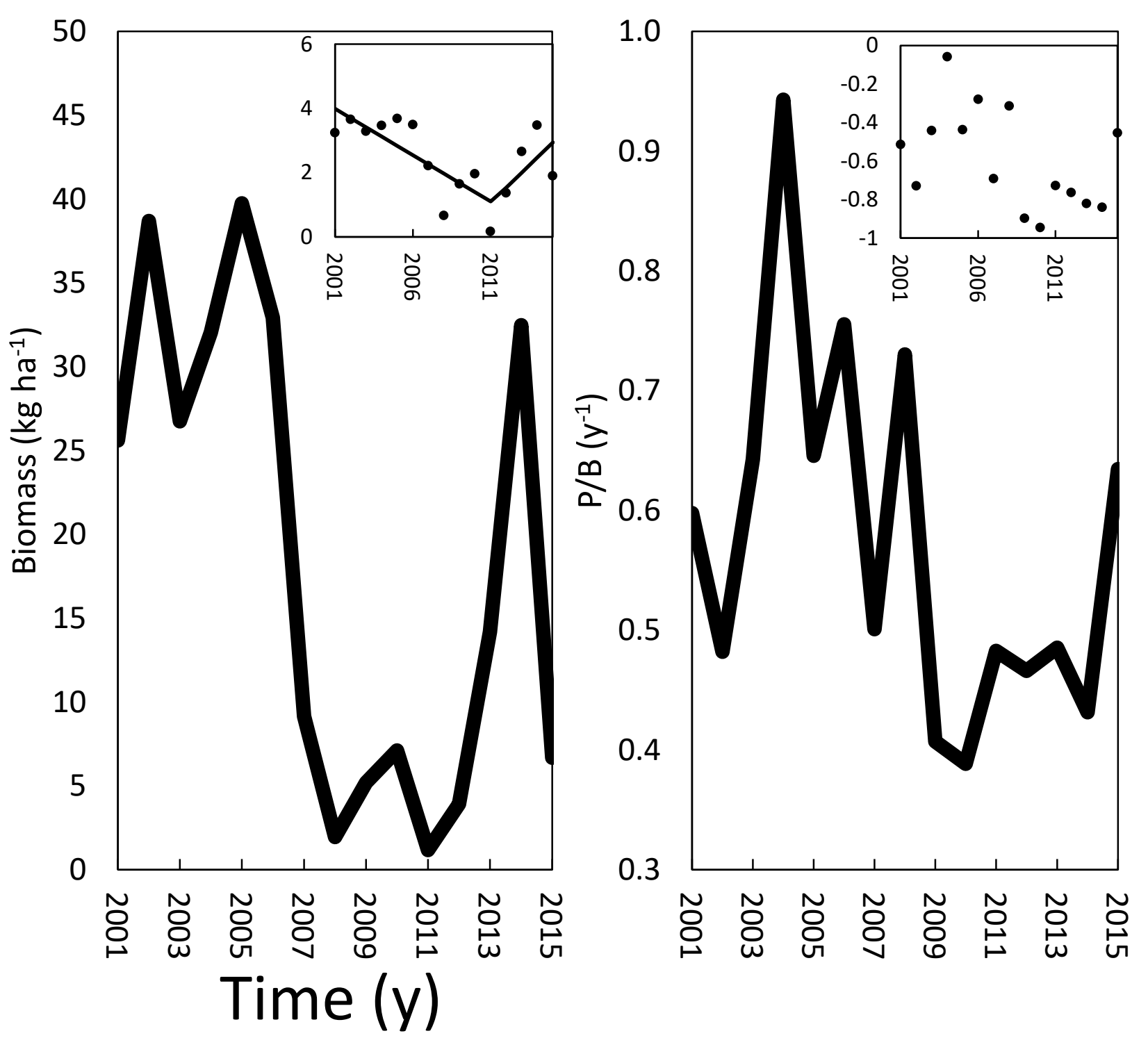

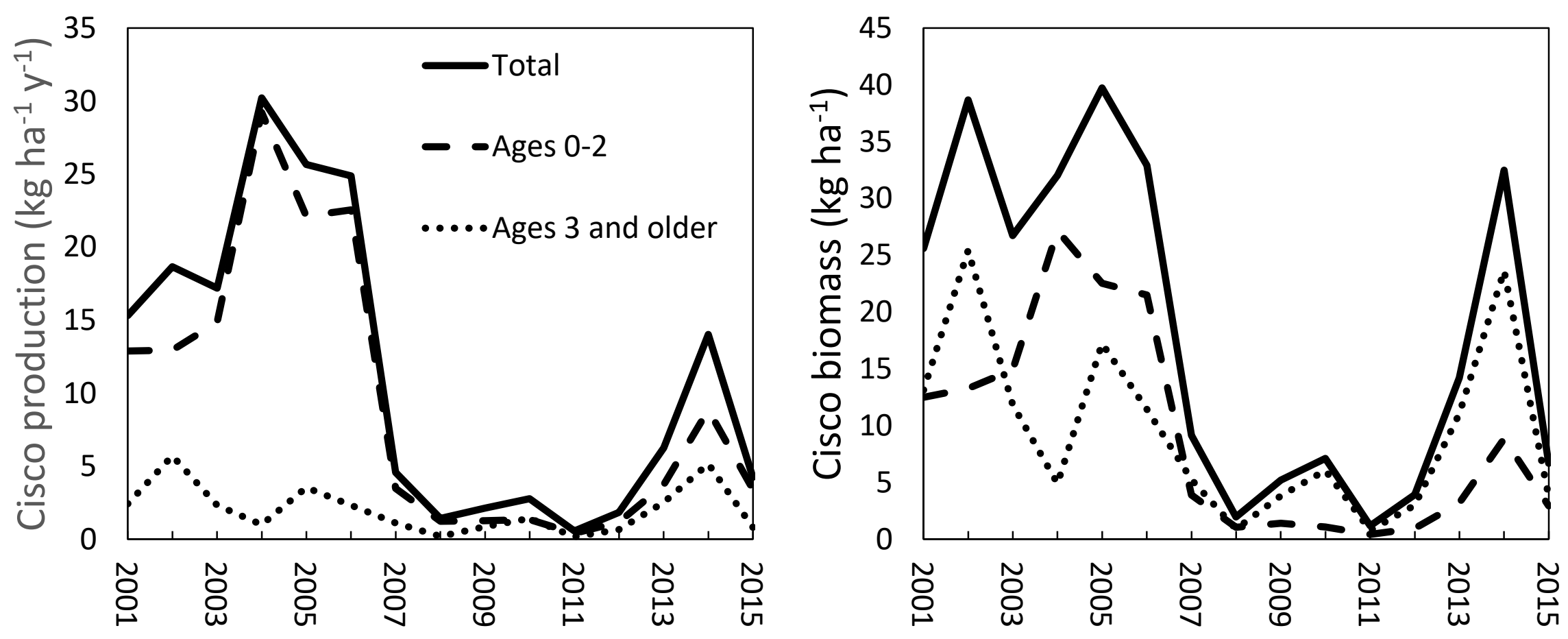

Time (y) 


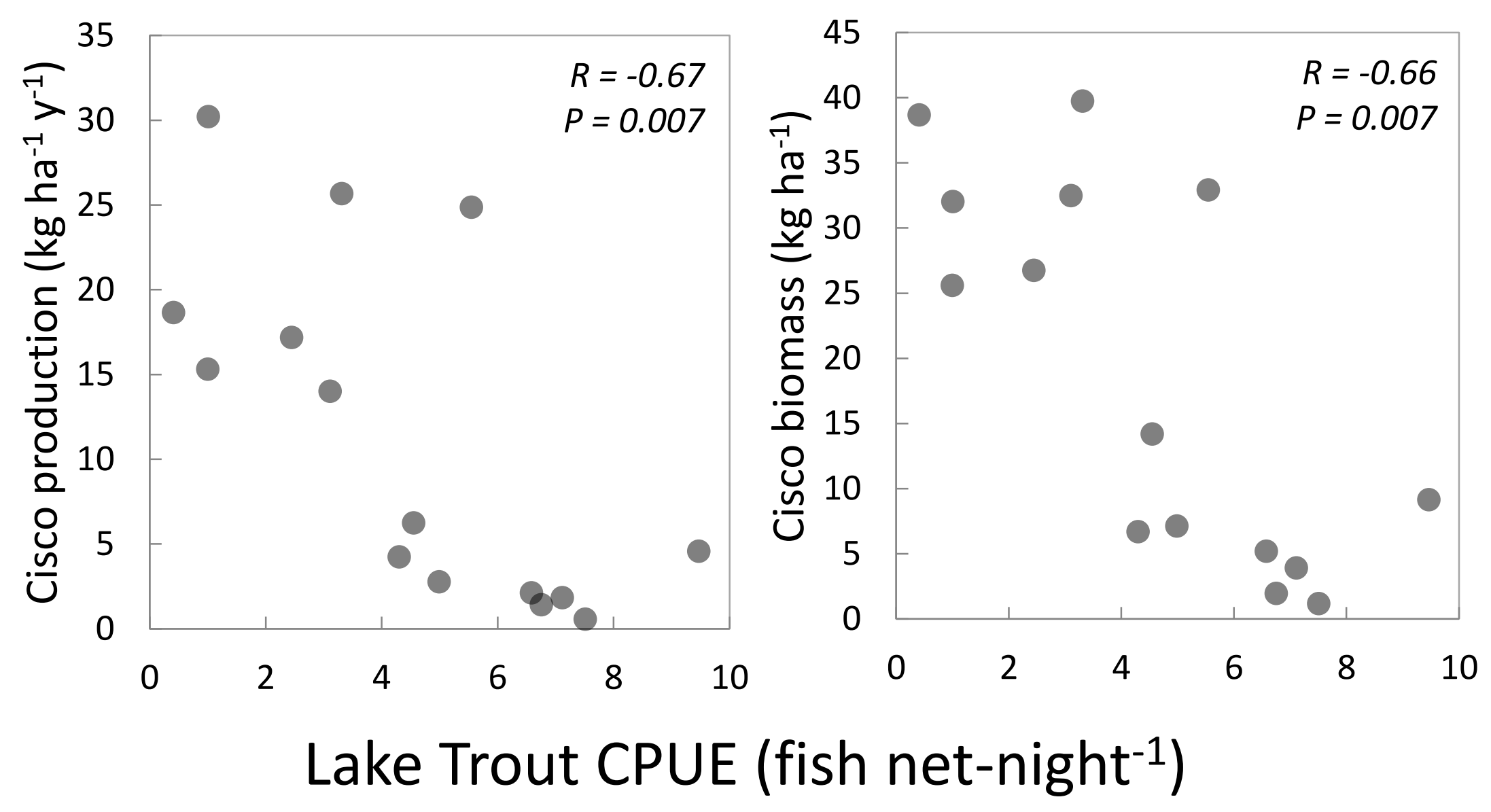

